\title{
Futuros creativos: estudiantes de comunicación audiovisual ante el diseño de contenidos televisivos
}

\section{Creative futures: students of audiovisual communication in the design of television contents}

\author{
Dra. Elena Medina de la Viña, Universidad Rey Juan Carlos (España) \\ elena.medina.delavina@urjc.es|http://orcid.org/0000-0003-2685-1033 \\ Dr. Julio Moreno Díaz, Universidad Rey Juan Carlos (España) \\ julio.moreno@urjc.es|http://orcid.org/0000-0002-5165-9310
}

\begin{abstract}
Resumen
Existen numerosos estudios que profundizan en el tipo de consumo de medios que hacen los jóvenes, cuya relación con la tecnología es habitual desde su infancia, así como el tiempo que dedican a ver televisión en los distintos terminales disponibles en la actualidad; sin embargo, sus preferencias a la hora de diseñar formatos para televisión están menos definidas. El objetivo principal de la presente investigación es determinar las tendencias de los y las estudiantes de Comunicación Audiovisual ante el proceso de creación de un formato de televisión, así como las innovaciones que podrían ofrecer en relación al uso de nuevas tecnologías en contenidos televisivos, teniendo en cuenta que los medios de comunicación, en general, y el campo concreto de la televisión, serían sus futuras áreas de trabajo. Para ello se realizó una experiencia con 688 alumnos y alumnas de la universidad Rey Juan Carlos de Madrid, organizados libremente en grupos de trabajo a lo largo de dos cursos lectivos, que dio como resultado la obtención de 123 formatos. Los resultados pusieron de manifiesto que estos jóvenes universitarios, lejos de ofrecer formatos novedosos que integren tecnología digital y nuevas pantallas, se ven influidos por lo que consideran formatos de éxito de la televisión actual, lo que debe llevarnos a una discusión más amplia sobre la creatividad en el entorno universitario y a cuestionarnos la formación en el mundo académico.
\end{abstract}




\begin{abstract}
There are numerous studies that deepen the type of consumption of media about young people whose relationship with technology is habitual since their infancy, as well as the time they devote to watching television in the different terminals available today; however, their preferences when designing TV formats are less defined. The main objective of this research is to determine the trends of Audiovisual Communication students in the process of creating a television format, As well as the innovations they could offer in relation to the use of new technologies in television content, keeping in mind that media in general, in particular the television, will be their future work area. To this end, an experience was carried out with 688 students from the Rey Juan Carlos University in Madrid. They were organized freely in working groups throughout two academic years. This resulted in the obtention of 123 formats. The results showed that these young university students are influenced by what they consider successful formats of the current television; far from offering novel formats that integrate digital technology and new screens. This should lead to a broader discussion about the creativity in the university environment and to ask about training in the academic world.
\end{abstract}

Palabras clave: alfabetización digital, formatos televisivos, estudiantes universitarios, nativos digitales.

Keywords: digital literacy, television formats, university students, digital natives.

\title{
1. INTRODUCCIÓN
}

En estos últimos años se ha producido un cambio en los medios de comunicación que nos ha conducido desde un modelo analógico hacia un modelo digital; mientras que los medios tradicionales escritos mantienen el mundo del papel en paralelo con el de la publicación electrónica, distribuida a través de internet, aún cuando han surgido nuevos medios con publicación exclusivamente en la red, en el medio televisivo el cambio se produjo en forma de apagón analógico, que en España fue en 2010, dando paso a una televisión digital que ha transmutado la llamada neotelevisión, autorreferencial y espectacular, en la que se producía una "disolución de los límites entre ficción y realidad" (Scolari, 2008: 5) hacia una nueva forma de ver y hacer televisión, la hipertelevisión, "una televisión más compleja, con muchas tramas narrativas, pantallas fragmentadas y ritmo acelerado. Una televisión que, en definitiva, imita la dinámica de los medios digitales interactivos" (Scolari, 2013) y que, además, permite una ampliación de los contenidos televisivos mediante narrativas transmedia para el disfrute y la participación de los usuarios, como una forma de enriquecer los contenidos de la televisión aprovechando las posibilidades que ofrecen las nuevas tecnologías e internet : "Con los Smart TV se está ante una audiencia digital televisiva en fase de consolidación 
(22\% de los internautas en 2014 según la IAB-Spain), con un perfil próximo a los millennials aunque en una franja superior de edad (30-44)" (Papí Gálvez, 2015: 163).

En medio de estos cambios, las audiencias de los canales de televisión tradicionales se mantienen en unas cifras muy importantes, si bien se confirma la tendencia de estos últimos años hacia un ligero descenso del consumo diario; según Barlovento Comunicación, en España en 2017 la media de consumo fue de 228 minutos por persona y día, sumando el consumo lineal y el diferido, lo que representa una bajada de 5 minutos respecto a 2016 que, a su vez, fue de 4 minutos menos que en 2015 (2018: 7), aunque se habla de un incremento del consumo televisivo "gracias a la suma del 'factor invitados', que Kantar Media y el mercado incorporaron a la medición de la audiencia televisiva en marzo 2017, [...] un total de 240 minutos por espectador y día" (Barlovento Comunicación, 2018: 7).

En el marco televisivo actual, este estudio pretende acercarse a las propuestas de formatos para televisión que formulan los jóvenes universitarios, en concreto los estudiantes de Grado en Comunicación de la Universidad Rey Juan Carlos de Madrid, con la intención de conocer en qué medida se puede hablar de propuestas novedosas por parte de los futuros creativos de televisión, entre cuyas preferencias, como usuarios, "la información no ocupa un lugar destacado entre los programas más vistos por los jóvenes, aunque entre las demandas por ellos expresadas, exijan una mayor presencia de información en las parrillas" (López Vidales y Gómez Rubio, 2014: 334).

\subsection{Objetivos e hipótesis}

La naturaleza de esta investigación nos permitió fijar una serie de objetivos relacionados con el diseño de nuevos formatos televisivos: el objetivo principal de la investigación fue determinar qué tipo de programas, con definición de género y formato, proponía el alumnado universitario que estudia el Grado en Comunicación, en concreto de la Universidad Rey Juan Carlos de Madrid; teniendo en cuenta que los medios de comunicación en general y, en buena medida, el campo concreto de la televisión, serán sus futuras áreas de trabajo, parecía pertinente conocer cuáles son sus inclinaciones a la hora de diseñar formatos televisivos.

Este objetivo principal nos ha permitido plantear otros objetivos específicos; en primer lugar, conocer si los jóvenes universitarios ofrecen innovaciones sustanciales con respecto a los formatos habituales de la televisión, diseñando formatos más arriesgados, en forma o en contenido, para las programaciones actuales. En segundo lugar, determinar hasta qué punto las nuevas tecnologías y sus aplicaciones formarían parte de estos nuevos formatos televisivos.

Estos objetivos nos han permitido plantear varias hipótesis; la primera es que estos jóvenes, aunque críticos con la televisión tradicional, están influidos por lo que representan los estándares 
de éxito de los contenidos televisivos actuales, lo que nos lleva a definir la segunda hipótesis: a consecuencia de la primera afirmación, los contenidos propuestos se mantienen dentro de los formatos predominantes en la televisión actual y dependientes de lo ya experimentado por los canales de televisión, públicos y privados, por lo que se presentan pocas innovaciones con un predominio de formatos de entretenimiento.

La tercera hipótesis es que las nuevas tecnologías no son elementos significativos a la hora de diseñar nuevos formatos, manteniéndose como herramientas de apoyo o de participación del espectador dentro del entorno de las redes sociales y de cometidos ya experimentados.

\subsection{Metodología}

La presente investigación se realizó en el marco de una experiencia formativa con el alumnado de los últimos cursos del Grado en Comunicación Audiovisual, en el seno de la asignatura Producción audiovisual: televisión y radio, que se imparte en el tercer curso de las titulaciones de Grado en Comunicación Audiovisual y en cuarto curso en los dobles grados que lo incluyen de la Universidad Rey Juan Carlos de Madrid; en ambos casos se trata de asignaturas obligatorias de 6 ECTS.

La muestra se recogió en los dos campus que imparten este grado, en todas las titulaciones que lo incluyen, Grado en Comunicación Audiovisual, Doble Grado en Periodismo y Comunicación Audiovisual y Doble Grado en Administración de Empresas y Comunicación Audiovisual, así como en todos los turnos horarios, con objeto de que la muestra fuera representativa tanto por titulaciones como por campus y turnos horarios.

El seguimiento se hizo a lo largo de dos cursos lectivos, con una participación de 422 alumnos y alumnas en 2015-16 y de 266 en 2016-17, representando un total de 688 participantes. Realizar la observación durante dos cursos permitiría averiguar si hay variaciones significativas de un año a otro.

El total de formatos obtenidos fue de 123, en la proporción que podemos observar en la tabla 1: 
Tabla 1. Reparto de formatos obtenidos

\begin{tabular}{|l|l|l|l|l|}
\hline Campus & $\begin{array}{l}\text { Doble Grado } \\
\text { Administración } \\
\text { de Empresas- } \\
\text { Comunicación } \\
\text { Audiovisual }\end{array}$ & $\begin{array}{l}\text { Grado en } \\
\text { Comunicación } \\
\text { Audiovisual }\end{array}$ & $\begin{array}{l}\text { Doble Grado } \\
\text { en Periodismo } \\
\text { - Comuni- } \\
\text { cación Audiovi- } \\
\text { sual }\end{array}$ & TOTALES \\
\hline Vicálvaro & 10 & 18 & 25 & 43 \\
\hline Fuenlabrada & 10 & 56 & 39 & 123 \\
\hline TOTALES & 10 & 74 & & \\
\hline
\end{tabular}

Fuente: elaboración propia

La elección de los alumnos y alumnas de tercero y cuarto para realizar esta investigación parecía idónea, ya que son los estudiantes de los últimos cursos, y por ello, los más próximos al desempeño de la vida profesional; por otra parte, en esa fase de su formación los participantes ya han adquirido los conocimientos y herramientas necesarios para desarrollar un diseño completo de un formato televisivo es decir, un paper format ${ }^{1}$.

La metodología utilizada fue cualitativa, basada tanto en la supervisión de la práctica a lo largo de un semestre completo de cada curso lectivo, como en el análisis de contenido de los proyectos obtenidos.

Los elementos que hemos tenido en cuenta para este estudio, en relación con los objetivos propuestos, fueron la variable de sexo, tanto sobre el total de participantes como de organización de grupos de trabajo, género y formato televisivo que presentan, perfil de presentador o presentadora que se propone y presencia de las nuevas tecnologías en los formatos presentados.

El alumnado se organizó libremente en grupos de trabajo con una media de seis personas cada uno, asumiendo el papel de una empresa productora, creadora de formatos televisivos, dotándose de un nombre y unos objetivos como productora; debían desarrollar un proyecto/ formato de programa de televisión para ser presentado a una cadena concreta, con el fin de llegar a un contrato de producción; el formato debía ser defendido posteriormente en un pitching ${ }^{2}$, ante sus compañeros y compañeras que, a su vez, asumían el papel de agentes de las cadenas de televisión, los docentes y un profesional del mismo área.

La elección del canal y el género del futuro programa fueron libres, con la excepción de formatos de ficción, único género no permitido, ya que se pretendía que los proyectos se vincularan a formatos exclusivos de televisión; todos los elementos integrantes del paper format 
debían ser adecuados y coherentes entre sí en cuanto a filosofía del programa, propuesta de medios, presentadores, invitados e invitadas, franja horaria, presupuesto, etc. Cada grupo de trabajo debía entregar su proyecto en soporte físico, con lo que este documento, básico en el diseño de un formato para televisión, permitió también recoger los datos que formarían parte de esta investigación y ordenarlos en tablas.

Las variables de sexo se han registrado para constatar si reflejaban datos diferenciados con respecto a la tendencia habitual en estas titulaciones; el resto de las variables suponen indicios significativos sobre la originalidad de los contenidos propuestos.

\section{JÓVENES Y TELEVISIÓN}

Los millennials, definidos por Howe y Strauss (2000) como las personas nacidas entre 1980 y 2000, representan, según Barlovento Comunicación, "el 20,1\% de la población de 4 o más años de edad de España, con 8,9 millones, una quinta parte del total de espectadores de TV" (2016: 3), pero su consumo de televisión es de 70 minutos menos que la media antes indicada (2016: 2), siendo T5 la cadena más vista, con una cuota del $14,9 \%$, seguida de $\mathrm{A} 3$, con un $11,4 \%$, y de las Temáticas de Pago, con un 9\%3; para ellos y ellas, la información se mezcla con el entretenimiento, "siendo la primera generación en abandonar el consumo masivo de televisión, mostrando su preferencia por el contenido online, especialmente por YouTube, en contraposición a la tradicional televisión en directo" (Álvarez \& de Haro, 2017: 355).

Algunos estudios señalan la importancia de este sector en distintos entornos relacionados con el consumo en Estados Unidos:

Alrededor de 75 millones de residentes están actualmente en edades comprendidas entre 18 y 34 años [...]. En 2050, el tamaño de este grupo de edad se habrá incrementado a 85 millones, equivalente al $21,4 \%$ del total de la población [...] Casi el $80 \%$ de los pertenecientes a la generación del milenio tienen un teléfono inteligente. Este factor es decisivo para las marcas, ya que los comentarios positivos en blogs, Twitter, YouTube o Facebook pueden hacerse virales en cuestión de segundos e influir en el comportamiento tanto de clientes existentes como de posibles clientes (Nava, Karp \& Nash-Stacey, 2014).

No obstante, algunos autores consideran que la edad, o la generación, no necesariamente aporta una diferencia notoria en cuanto al uso de las nuevas tecnologías, pues esta consideración sobre los y las millennials puede ocultar las diferencias de uso que existen entre los jóvenes y "naturaliza un proceso que requiere de una fuerte socialización en el uso de estas herramientas digitales” (Tejerina, Aldekoa \& García, 2017: 372); en consonancia con esta opinión, Álvarez 
y de Haro señalan que "debemos estar vigilantes sobre las brechas digitales que surgen en la misma generación y todavía la importancia de variables demográficas como género, renta, educación y similares, que influyen de manera importante en el cambio" (2017: 365). A ello debe añadirse la formación académica del alumnado, pues no siempre su formación universitaria contempla un desarrollo adecuado de estas herramientas; en el caso de los y las estudiantes de comunicación "Si bien son prosumidores transmedia en su vida extraescolar, la mayoría de los jóvenes profesionales que salen de las universidades fueron formados para la producción monomediática" (Scolari, 2017).

Existen muchos estudios anteriores que han profundizado en el tipo de consumo de medios que hacen estos jóvenes cuya relación con la tecnología es habitual desde su infancia: viven conectados al teléfono móvil y a internet y su opinión con respecto a la televisión tradicional no es muy buena: "los jóvenes de 18 a 25 años, definen la televisión como telebasura [...] el exceso de reality shows y de programas con personajes que poco o nada tienen que ver con la profesión, la convierten en una televisión de poca calidad" (López, Medina \& González, 2013); cuando se trata de conocer sus áreas de interés "cine, opinión, informativos y musicales son los géneros señalados como favoritos [...] Por el contrario, entre los géneros minoritarios figuran el entretenimiento y el magazine" (López \& Gómez, 2012: 279), y afirman ver la televisión como medio de entretenimiento e información; este dato estaría en consonancia con la respuesta mayoritaria que dan los jóvenes cuando se trata de definir su programación televisiva, pues según estas autoras los jóvenes de 14 a 25 años eligen como primeras opciones el entretenimiento y la actualidad (2012: 280). En cualquier caso, la televisión se sigue percibiendo como una opción de ocio, aunque el modo de verla de los jóvenes haya cambiado, pues el desarrollo de otros soportes tecnológicos caracterizados por la portabilidad está implicando que la juventud dedique cada vez más tiempo al entretenimiento audiovisual, aunque lo que antes se centraba más en la TV ahora se consume a través de otros dispositivos y en cualquier lugar (Tejerina, Aldekoa \& García, 2017: 342).

Es en este punto donde pretendemos situar esta aportación: si bien los gustos de la juventud, en cuanto al consumo televisivo se refiere, aparecen bastante definidos en función de los estudios antes señalados, sus preferencias a la hora de diseñar formatos para televisión lo están en menor medida. Así pues, se trata de conocer el interés de estos jóvenes millennials cuando deben crear formatos televisivos susceptibles de ser producidos para los canales de televisión, es decir, formatos realizables en el entorno televisivo actual, y saber hasta qué punto las nuevas 
tecnologías se introducen en estos formatos, más allá de las herramientas de captación y postproducción de las imágenes.

\section{LOS FORMATOS TELEVISIVOS}

Para Inmaculada Gordillo (Gordillo et al., 2011: 94), "a partir de la neotelevisión, el sincretismo, la hibridación y el reciclaje se convierten en los rasgos más sobresalientes de la programación televisiva", lo que complica la definición de formato televisivo, pues "Los géneros tradicionales se entrecruzan, constituyendo formatos novedosos y eclécticos en rasgos formales y de contenido" (Gordillo et al., 2011: 94).

Podemos decir que la catalogación habitual de los programas de televisión se realiza según el género, el subgénero y el formato, entendiendo que el género definirá los aspectos más generales que caracterizan al conjunto de programas que guardan relación entre sí. [...] El subgénero hace referencia a los diferentes grupos que componen los géneros y que mantienen las características que lo identifican a la vez que lo concretan y diferencian (Moreno y Medina, 2017: 67)

Mientras que el formato se relacionaría con los aspectos que diferencian a unos programas de otros, en palabras de Gloria Saló "el desarrollo concreto de una serie de elementos audiovisuales y de contenidos, que conforman un programa determinado y lo diferencian de otros" (Saló 2003: 13).

Somos conscientes de que en la televisión actual se da una hibridación tanto de géneros como de formatos, en la que "lo real y lo ficticio se funden hasta confundir sus fronteras" (Gordillo, 2004). Para Imbert, esta desaparición de límites entre "grandes géneros canónicos surge precisamente de la aparición de una especie de no man's land, un espacio narrativo inédito donde se con-funden los géneros estancos y se entrecruzan las funciones" (2011: 16), de forma que la división de géneros según los objetivos fundacionales de la televisión es confusa, dándose una permeabilidad de las funciones de la televisión como medio de información, de entretenimiento y de formación (Imbert, 2011). Así pues, aunque no existen definiciones estándar, y aceptadas de forma general, de género y formato televisivo, para este estudio tendremos en cuenta las definiciones anteriores.

Pero el concepto de formato tiene otra acepción dentro de la industria de la televisión, que es la referida al documento mismo que contiene el diseño completo de un programa televisivo y que es susceptible de compra-venta y adaptación. En este sentido, González considera que se pueden diferenciar dos modelos de formato:

En primer lugar se encuentra el formato escrito, o paper format, consistente en un texto detallado que comprende una descripción de la idea básica del programa proyectado, 
su contenido, su estructura y su estilo, y que se utiliza como herramienta comercial: es lo que se presenta a la productora para que estudie su viabilidad y decida sobre su adquisición con el fin de realizar la correspondiente obra audiovisual. En segundo lugar está lo que se conoce como formato del programa de televisión en sentido estricto, o formato tv ( $t v$ format), compuesto por el acumulado de los conocimientos adquiridos durante el proceso de producción del programa televisivo y que permite a otra productora realizar en cualquier territorio el mismo programa que fue originariamente producido en otro lugar (González, 2001: 31).

En este trabajo se ha considerado el concepto de paper format según se describe en primer lugar, como creación original de un formato de televisión.

\section{RESULTADOS}

Como ya se ha comentado, el total de alumnos y alumnas participantes fue de 688, y los grupos de trabajo resultantes, 123, cada uno de ellos con un formato diferente.

\subsection{Equipos de trabajo}

Encontramos una proporción mayor de mujeres, ya que estas representaron el $62,2 \%$ de los participantes, siendo la representación masculina del 37,7\% restante, datos que se mantienen dentro de la tónica general en esta titulación: "como ya viene siendo habitual en las titulaciones relativas a las ramas de Ciencias de la Comunicación, el perfil es principalmente femenino" (Marta \& Gabelas, 2013: 19); estos datos están en la línea de los ofrecidos por el Ministerio de Educación, Cultura y Deporte en el curso 2015- 2016 si bien, en nuestro caso, el porcentaje de hombres es un poco menor y el de mujeres un poco mayor, ya que en la publicación Datos y cifras del sistema universitario español, se señala que en los grados pertenecientes al área de Ciencias Sociales y Jurídicas, en la que se encuadran los estudios de Comunicación, el porcentaje de hombres matriculados es del $40 \%$ y el de las mujeres del $60 \%$. En relación a estos datos también hemos observado la composición de los grupos, ya que se dieron tres casuísticas: la mayoría se conformaron como grupos mixtos, pero también se organizaron grupos de trabajo únicamente de chicas, dieciséis equipos, y tres casos solo de chicos; la proporción fue la siguiente: 
Figura №. 1. Composición de los grupos participantes

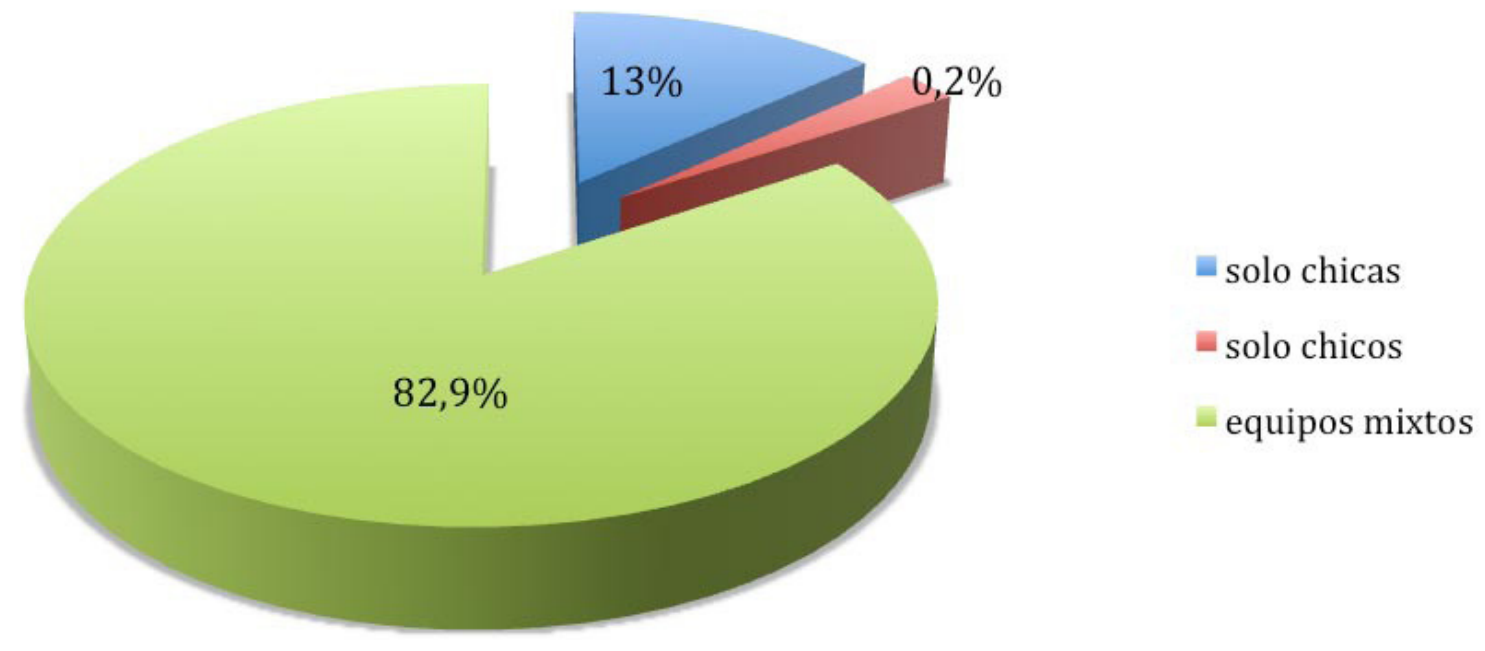

Fuente: elaboración propia

Esta organización de los grupos no tuvo una repercusión significativa en los formatos propuestos, pues se observó una homogeneización en cuanto al tipo de programas elegidos, como veremos a continuación.

\subsection{Géneros $\mathbf{y}$ formatos resultantes}

Para la consideración de los proyectos presentados tendremos en cuenta la división clásica antes mencionada de Género informativo, Género divulgativo y educativo, Ficción y Entretenimiento, con la salvedad de la Ficción, ya que los grupos de trabajo no podían presentar este tipo de contenidos.

Según esta descripción, la mayor parte de los proyectos presentados se vinculan al género de entretenimiento, 116 proyectos, lo que supone el $94,3 \%$ de los formatos presentados, y en muy pequeña proporción al divulgativo con 7 , un $5,7 \%$; no se ha presentado ningún paper format que se pueda definir como perteneciente al género informativo o al educativo.

Eliminados los contenidos de ficción, estos datos no coinciden con los porcentajes de programación de las cadenas, pues los programas de entretenimiento, incluyendo los concursos, representan un $12,3 \%$ en el total de las cadenas, lo que supone el cuarto puesto en porcentajes de programación; en primer lugar estaría la ficción, con un 41,3\%, en segundo lugar, los programas 
culturales, con18,6\%, y en tercer lugar, los deportes, con $13,7 \%$, según los datos de Barlovento Comunicación (2018).

Sin embargo, sí podemos decir que estarían en sintonía con los cincuenta programas más vistos de 2017 en España, si bien los programas dedicados a las retransmisiones de las distintas ligas y campeonatos de fútbol acaparan los datos de audiencia más altos. Según los datos aportados por Barlovento Comunicación (2018: 31), de los 50 programas más vistos, el $78 \%$ son emisiones deportivas, con 39 programas; las emisiones relacionadas con el fin de año representan el $8 \%$, con cuatro emisiones; los musicales, el 4\%, con dos emisiones, correspondientes al Festival de Eurovisión; la ficción, otro $4 \%$, y finalmente el entretenimiento representó el 6\%, con tres emisiones, situándose en las posiciones 33, 34 y 48 del ránking.

Mucho más dispersos son los datos relativos a los formatos, fruto de la hibridación de éstos que los jóvenes universitarios también han manifestado. Dentro de los formatos de entretenimiento, los relacionados con la telerrealidad, con un amplio abanico de variantes, son los más representados, con 58 proyectos que suponen el $50 \%$ de los formatos de entretenimiento, seguido de los formatos concurso, magazine y talent show, según puede verse en el gráfico siguiente:

\section{Figura $\mathbf{N}^{\circ}$. 2. Distribución de los formatos de entretenimiento presentados}

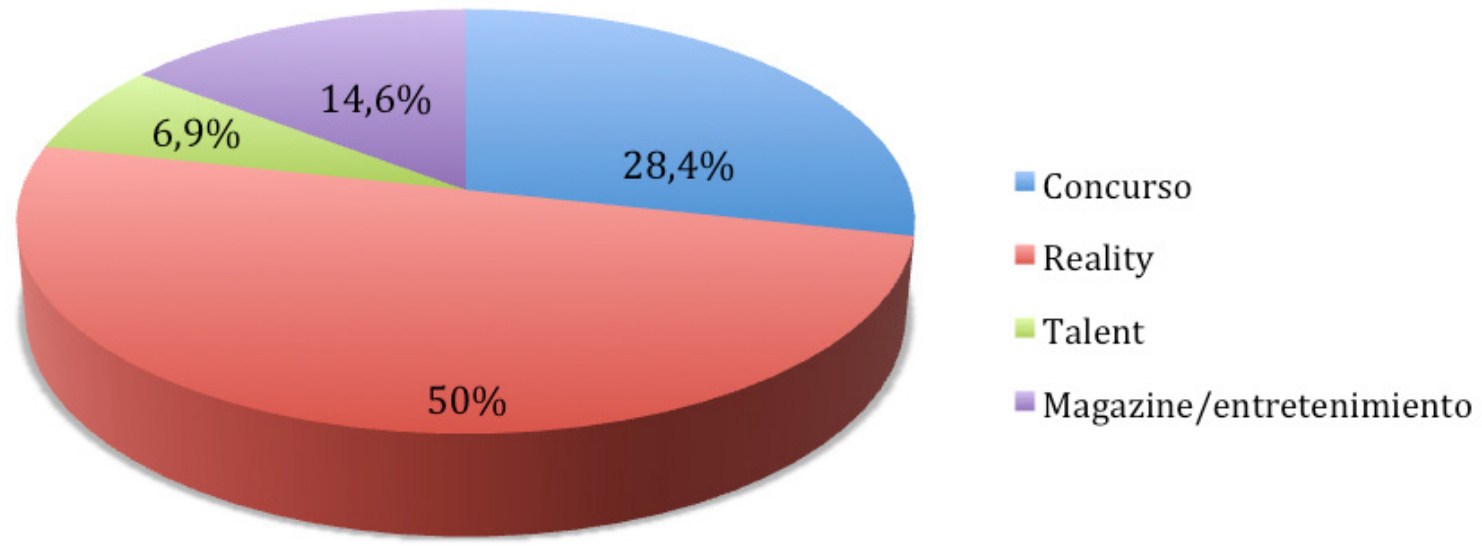

Fuente: elaboración propia 
Los concursos están bien representados, con 33 proyectos aportados, si bien las referencias estilísticas que se han podido observar remiten a los formatos espectaculares de los años noventa, quizás por influencia de lo que puede constituir el recuerdo televisivo de su infancia; en general son concursos espectáculo basados en la competición física y la habilidad, en combinación con conocimientos; también hemos podido comprobar que algunos formatos incluían la tematización semanal ${ }^{4}$, tan presente en los concursos de los años noventa. Como sus precedentes, la mayoría de estos formatos aparecen ubicados en la franja del prime time. Todo ello coincide con la afirmación de que "Los programas de televisión que mejor recuerdan quienes tienen ahora menos de 30 años son: Doraemon, El Gran Prix y Operación Triunfo" (Samsung, 2016).

Si bien en los estudios anteriores los jóvenes, en su papel de espectadores y espectadoras, denunciaban un exceso de reality show en las programaciones, cuando se trata de diseñar un nuevo formato para la televisión actual repiten el modelo conocido, y el reality sigue siendo el de mayor incidencia; la presencia más importante es la del docu reality, con 21 proyectos, seguido del reality game, con 16 , y del reality show, con 12; el dating show estuvo presente con 7 formatos y el reality coach es el menos representado, registrándose solamente dos paper format, según puede verse en el siguiente gráfico:

\section{Figura $\mathrm{N}^{\circ}$. 3. Distribución de los formatos reality presentados}

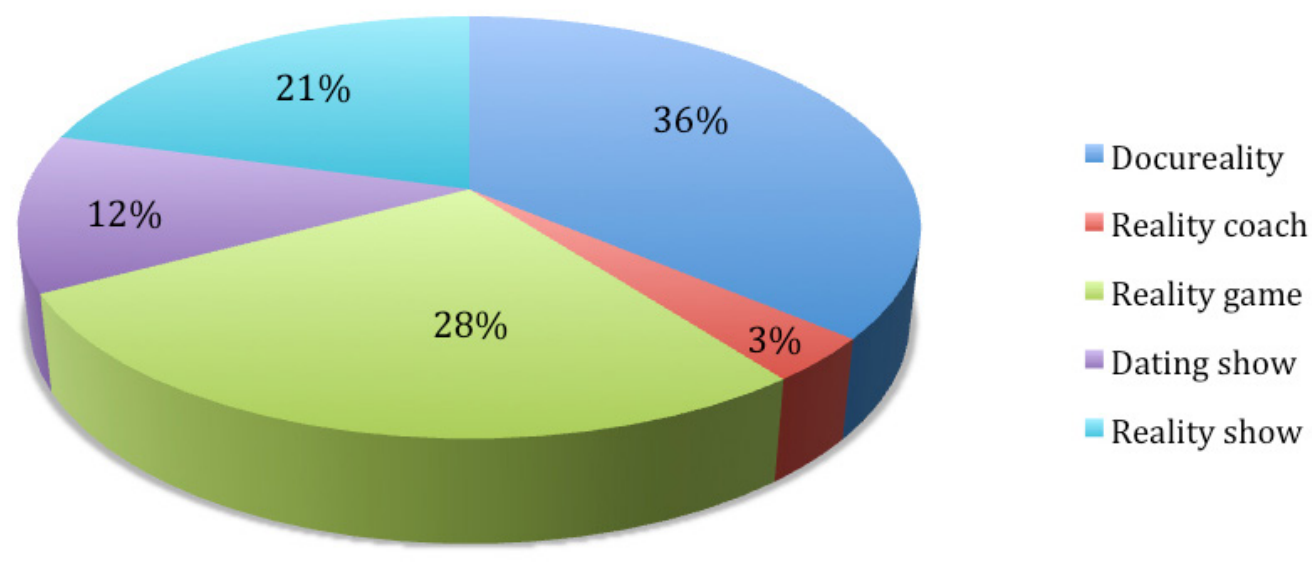

Fuente: elaboración propia 
Encontramos formatos tradicionales de convivencia, reality show, con muy pocas variaciones con respecto a los actuales en programación, pero también otros de más reciente aparición en las cadenas españolas, como el dating show; generalmente las dinámicas de los programas son las mismas que las de los programas en emisión, modificándose únicamente el contexto en el que se produce la convivencia o el estatus y condición social de los y las participantes: sustitución de la "casa" por la recreación de un centro comercial después de una catástrofe, supervivencia frente a un grupo de zombis, o el enfrentamiento y/o convivencia entre jóvenes y mayores, "urbanitas" y "rurales", etc. También en este caso tendríamos que considerar la influencia de los formatos actuales y la tendencia de los jóvenes a repetir aquello que consumen: en febrero de 2016 los espectadores de Gran Hermano de entre 13 y 24 años representaron "una cuota del 30,8\%. Es decir, prácticamente, uno de cada tres jóvenes se decantó este jueves por la noche por ver Gran Hermano VIP" (Redondo, 2016).

Aunque la gran familia de los realities es difícil de clasificar, dada su evolución en el tiempo y sus progresivas hibridaciones con otros formatos, en este estudio nos hemos ajustado a una serie de definiciones que permitieran incluir los proyectos diseñados por los y las participantes; de esta forma, definimos el docu reality como la hibridación entre el seguimiento de la realidad, que aporta el documental, con la espectacularización propia de los programas de telerrealidad; el reality coach como programas de "asesoramiento y ayuda para desarrollar acciones o habilidades de todo tipo" (Lamarca, 2009); en el caso del reality game entendemos que se trata de una "combinación del reality show con el concurso" (Guerrero, 2010: 188), válida para las propuestas presentadas; el dating show, como "programas basados en la seducción, citas, erotismo y, en definitiva, en las relaciones personales entre los concursantes con el toque correspondiente de telerrealidad" (Moreno \& Medina, 2017: 67); por último, el reality show aparece en los formatos registrados como el formato de telerrealidad basado en la convivencia de un grupo de personas.

\subsection{Target de los formatos}

En cuanto al público objetivo de los formatos presentados, encontramos que los espectadores infantiles son los menos representados, solo cuatro programas, junto con el público de más de 35 años, con tres; se tiende a un abanico muy amplio de edad en el que aparecen formatos para todos los públicos, partiendo de un perfil muy joven, entre los 12 y los 15 años, en su mayoría, incluso en formatos destinados a la franja de Noche 1 o Prime Time.

El target en la medición de audiencias se analiza según cinco franjas de edad: de 4 a 12 años, de 13 a 24, de 25 a 44, de 45 a 64 y más de 64 años. Sin embargo, los grupos de trabajo presentaron públicos objetivos que tenían más que ver con su concepto de joven que con la 
división generalizada arriba indicada; de esta forma sus franjas parten de los 12 años, salvo los programas infantiles, y generalmente marcan un límite máximo en los 35 ó 45 años, definiendo con ello que el formato está destinado a un público joven. No aparece una definición de público receptor por encima de estas edades, salvo para señalar que el formato tiene un target muy amplio.

La franja más destacada es la de un público de más de 18 años, si bien, como decíamos, en los estándares de estudios de audiencias este segmento quedaría englobado en el de 13 a 24 años.

En todos los casos se estaría hablando de un público objetivo joven, que se sitúa en un abanico de edad que está próximo al rango de los autores y autoras de estos formatos, ya que únicamente un $3 \%$ de los formatos presentados abarcaría a un público de más de 35 años.

\subsection{Presencia de las nuevas tecnologías}

Otro rasgo común en los paper format presentados es que en ellos se explotan muy poco las nuevas tecnologías, que aparecen como herramientas de apoyo de los participantes en los concursos o como posibilidades de votación y participación del espectador; pero lo hacen de la misma forma en la que actualmente se traduce esta participación, mediante las redes sociales con las que el espectador o espectadora puede opinar y votar con una participación limitada; esta falta de aplicación de las nuevas herramientas en formatos televisivos está en sintonía con la afirmación de que los millennials universitarios "se están mostrando como 'tecnoanalfabetos funcionales' al hacer un uso muy limitado, y principalmente restringido al aspecto personal y lúdico, obviando las ventajas profesionales que podrían aprovechar de cara a su próxima inserción laboral" (Ruiz, Ruiz \& Galindo, 2016: 99). Si su consumo audiovisual está orientado al entretenimiento, el uso de las nuevas tecnologías y de las amplísimas posibilidades de las aplicaciones digitales queda también limitado a este campo del disfrute del usuario y no tanto a la posibilidad de ampliación de los formatos, como ya ocurre en la televisión actual.

\subsection{Los rostros y las voces de los programas}

Con respecto a los presentadores y presentadoras, conductores de los formatos propuestos, se produce un cambio en los dos momentos del estudio; mientras que en el curso 2015-2016 aparecen 36 formatos conducidos por hombres y 31 por mujeres, en el curso 2016-2017, del total de 46 formatos presentados encontramos 24 conducidos por presentadores y 22 por presentadoras. 
En total tenemos 60 formatos cuyos presentadores son hombres y 53 con mujeres; la representación de género tiende a ser equitativa en el segundo período de la investigación, mientras que en el primero se produce una ligera mayoría de presentadores hombres.

En cuanto a los nombres propuestos encontramos poca novedad con respecto a los formatos en emisión: en general tienden a repetir los nombres ya reconocidos en las programaciones actuales, así como su dedicación, es decir, se asocian con aquellos perfiles por los que son más reconocidos, como presentadores de concurso, de magazine, etc. entre los hombres, el nombre más repetido es el de Arturo Valls, con ocho formatos, seguido de Juanra Bonet y Christian Gálvez, con cuatro formatos cada uno; en cuanto a las mujeres, Raquel Sánchez Silva aparece como conductora de seis formatos, seguida de Luján Argüelles y Lara Álvarez, con cuatro programas cada una. En el resto de los proyectos aparecen otros nombres conocidos, como Paula Prendes, Mercedes Milá, Nuria Roca, Jesús Vázquez o Carlos Sobera, entre otros muchos; en este caso interesa señalar que en muy pocas ocasiones se apuesta por rostros nuevos, o menos conocidos por el público; aún tratándose de un paper format creado en el ámbito universitario, diseñar un formato que sea defendible como una opción real para las cadenas actuales influye en los alumnos y alumnas, que se inclinan por aquellos nombres cuyo perfil es más idóneo para la cadena elegida en la actualidad, por lo que asumen menos riesgos a la hora de proponer otros nombres menos conocidos.

\section{DISCUSIÓN Y CONCLUSIONES}

Aunque coordinada por el profesorado, se trató de una experiencia colaborativa en la que el alumnado investigó, tanto el proceso de diseño de un formato televisivo de manera profesional, como las opciones creativas para ofrecer un formato de interés para las programaciones de las cadenas de televisión. El desarrollo de los proyectos fue un proceso totalmente independiente por parte del alumnado, que tomó decisiones creativas y técnicas, asumiendo el profesorado un papel de orientadores. Ello obligó a los participantes a poner en práctica destrezas y herramientas adquiridas en diferentes asignaturas para lograr el diseño de un formato en cada grupo de trabajo, al tiempo que cada uno de ellos debía responsabilizarse de su aportación concreta dentro del equipo.

A la hora de considerar los formatos presentados hemos podido confirmar que las propuestas se mantienen dentro de las líneas de programación actuales de las cadenas, es decir, existe una prevalencia del género de entretenimiento con fuerte presencia de los formatos vinculados a la telerrealidad, seguidos de los concursos, en sintonía con los datos obtenidos de las audiencias. 
Así, aunque los jóvenes se muestran poco receptivos hacia la programación actual de las cadenas de televisión, cuando ejercen de creativos sus diseños están en la línea de los ofrecidos por la televisión tradicional, con pocas variaciones, que podríamos calificar como de contexto: el lugar o la forma en la que se hace la convivencia en un reality o el tipo de participantes.

Esto nos lleva a considerar que el hecho de tener que defender un formato con posibilidades comerciales les hace dependientes de los modelos de éxito probado, que se refleja también en la elección de presentadores y presentadoras reconocidos, así como la franja horaria elegida, de máxima audiencia, en consonancia con un público objetivo que prima un abanico amplio de edades, con muy poca incidencia en los más jóvenes.

Con respecto a la utilización de nuevas tecnologías como parte integrante del formato, se ha podido apreciar una limitación importante, repitiéndose la función más habitual de uso de redes sociales como opinión, nominación o puntuación por parte de los espectadores y espectadoras, y primando el uso y disfrute, individual, como parte del entretenimiento; el concepto de formato televisivo que diseñan está más en la línea de la televisión tradicional que en la búsqueda de otras opciones que integren las distintas pantallas que manejan y que permitan desarrollar otras posibilidades; esta conclusión está en sintonía con otros estudios que han demostrado las carencias de los jóvenes en la utilización de las nuevas tecnologías (Gavilán, Martínez-Navarro \& Fernández-Lores, 2017), aunque ya existen ejemplos de formatos que proponen la integración de participantes y espectadores, así como el uso de distintas pantallas; es el caso de Lost in Time, creado por The Future Group, Fremantle Media, Ross Video y Epic Games, un "concepto de televisión lineal junto a un entorno de videojuego dando lugar a un formato híbrido que se ha dado en llamar Interactive Mixed Reality" (Panoramaaudiovisual.com, 2017); se trata de un formato en el que no solo los y las participantes juegan en una realidad virtual, como en un videojuego, sino que mediante una aplicación "los espectadores en casa pueden jugar contra los concursantes o con otros jugadores de todo el país en tiempo real" (Panoramaaudiovisual.com, 2017).

Estas conclusiones deben llevarnos a una discusión más amplia sobre la creatividad en el entorno universitario y a preguntarnos sobre la formación en el mundo académico; si la juventud se deja llevar por lo que consideran formatos de éxito y no son conscientes de que ellos y ellas son la nueva generación que debe protagonizar los cambios, es posible que tengamos que cuestionarnos nuestros métodos educativos a lo largo de todo el proceso formativo, en el sentido de que es preciso reforzar su capacidad creativa y no tanto un aprendizaje que los lleve a reproducir modelos que probablemente sean caducos cuando ellos asuman responsabilidades laborales . 
Por otra parte, sería deseable una mayor formación crítica en competencias digitales y nuevas tecnologías en el curriculo formativo de los jóvenes, pues hemos comprobado que ser nativos digitales no otorga de forma automática su conocimiento; este proceso requiere, a su vez, una mejor "estructuración de los planes de formación del profesorado en relación a las tecnologías de la información y comunicación" (Fernández-Cruz \& Fernández-Díaz, 2016: 104), pues esta formación debería iniciarse en las primeras etapas formativas.

\section{NOTAS}

${ }^{1}$ Paper format o formato escrito es un documento que contiene todos los datos de un futuro programa de televisión: género, estructura y secciones, estilo y puesta en escena, sinopsis, escaleta, guión, presupuesto, propuesta de equipo, perfil de participantes e invitados, público objetivo.

${ }^{2}$ Evento en el que se realiza una presentación verbal de un proyecto audiovisual con el objeto de obtener financiación, vender un formato de televisión u obtener la distribución del producto.

${ }^{3}$ Según el Informe de Barlovento Comunicación a partir de datos de Kantar Media.

${ }^{4}$ Se refiere al cambio de imagen y contenido semanal de los programas de televisión, en función del tema tratado; ello condiciona el tema de las preguntas de los concursos, así como la escenografía y el vestuario.

\section{REFERENCIAS}

Alvarez, J. M., \& de Haro, G. (Coord.). (2017). Millennials. La generación emprendedora. Madrid: Fundación Telefónica, Editorial Ariel. Recuperado de https://goo.gl/yiVSBr

Barlovento Comunicación (2016). Análisis televisivo 2015. Madrid: Barlovento Comunicación. Recuperado de https://goo.gl/eLjAaF

Barlovento Comunicación (2017). Análisis televisivo año 2016. Madrid: Barlovento Comunicación. Recuperado de https://goo.gl/yiVSBr

Barlovento Comunicación (2018). Análisis televisivo año 2017. Madrid: Barlovento Comunicación. Recuperado de https://bit.ly/2LpOmes.

Barlovento Comunicación (2016). Los milennials y la Tv: qué programas ven y cómo consumen. Madrid: Barlovento Comunicación. Recuperado de https://goo.gl/mVj9Hk. Carrasco, A. (2010). Teleseries: géneros y formatos. Ensayo de definiciones. Miguel Hernández Comunication Journal,1, 174-200. Recuperado de https://goo.gl/LpHPZf. 
Fernández-Cruz, F. J. \& Fernández-Díaz, M. J. (2016). Los docentes de la Generación Z y sus competencias digitales. [Generation Z's Teachers and their Digital Skills]. Comunicar, 46(XXIV), 97-105. Recuperado de http://dx.doi.org/10.3916/C46-2016-10

González, A. (2001). La tutela de los formatos televisivos. PEI Revista de propiedad intelectual. Septiembre diciembre, nº $^{\circ}$. Recuperado de: https://bit.ly/2L640zt

Gordillo, I. (2004). Reciclaje e Hibridación en los Nuevos Formatos Televisivos. En Mínguez, N. \& Villagra, N. (Ed.), La Comunicación: Nuevos Discursos y Perspectivas (pp. 8-15). Madrid: Edipo.

Gordillo, I., Guarinos, V., Checa, A., Ramírez, M. M., Jiménez, J., López, F. J., de los Santos, F. \& Pérez, M. A. (2011). Hibridaciones de la hipertelevisión: información y entretenimiento en los modelos de infoentertaiment. Revista Comunicación, 9(1), pp. 93-106. Recuperado de https://bit.ly/2uvJg9N

Howe, N., \& Strauss, W. (2000). Millennials Rising: The Next Great Generation. New York: Vintage Books.

Gavilán, D., Martínez-Navarro, G. \& Fernández-Lores, S. (2017). Universitarios y redes sociales informativas: escépticos totales, moderados duales o pro-digitales. [University Students and Informational Social Networks: Total Sceptics, Dual Moderates or Pro-Digitals]. Comunicar, 53(XXV), 61-70. Recuperado de https://doi.org/10.3916/C53-2017-06.

Guerrero, E. (2010). La irrupción del reality game en la televisión española y sus efectos sobre los concursos. Vivat Academia, 110(XIII), 182-216. Recuperado de https://doi.org/10.15178/ va.2010.110.182-216.

Imbert, G. (2011). De la hibridación a la licuefacción de las categorías e identidades en la postelevisión. Quaderns del CAC, 36(XIV)(1), 15-20. Recuperado de https://goo.gl/AVpQ1A.

Lamarca, M. J. (2009). El reality show en España. Post en La Artes@ Digital. Recuperado de https://goo.gl/YnjxfS.

Lopez, N. \& Gomez, L. (2012). Géneros, formatos y programas de televisión preferidos por los jóvenes. Análisis comparativo por comunidades autónomas. Icono14 10(3), 258-283. Recuperado de https://doi.org/10.7195/ri14.v10i3.209.

López, N., Medina, E. \& Gonzalez, P. (2013). Los jóvenes españoles demandan una televisión con más ficción y entretenimiento. Ámbitos. Revista Internacional de Comunicación, 22. Recuperado de https://goo.gl/YHL44e. 
López Vidales, N.; Gómez Rubio, L. (2014). Nuevos hábitos de los jóvenes españoles y tendencias de futuro en el consumo de radio y televisión. Historia y Comunicación Social, 19, 327-340. Recuperado de https://bit.ly/2Jx71mO.

Marta-Lazo, Gabelas-Barroso, (2013). Hábitos de consumo televisivo de ficción entre los universitarios que estudian comunicación. Revista de Comunicación de la SEECI, 31(XVII), 14-33. Recuperado de https://goo.gl/7 JiMyN.

Moreno, J. \& Medina, E. (2017). La producción de concursos en las cadenas de TV españolas: la espectacularización del formato (1990-2000). Comunicación y Medios, 35, 64-79. Recuperado de doi:10.5354/0719-1529.2017.46395

Nava, M., Karp, N, \& Nash-Stacey, B. (2014). La paradoja de la generación del milenio. Servicio de Estudios del BBVA de EEUU del Banco Bilbao Vizcaya Argentaria. Recuperado de https://goo.gl/ZvtmpN.

Recui, N. (2015). Las audiencias televisivas y las audiencias online en publicidad: ¿Diferencias y semejanzas?. En Quintas, N. \& González, A. (coord.), La participación de la audiencia en la televisión: de la audiencia activa a la social (pp. 150-166). Madrid: AIMC. Recuperado de https://goo.gl/Kw2tn2.

Redondo, D. (2016). GH VIP lidera y arrasa entre los jóvenes. Cadenaser.com. Recuperado de https://goo.gl/Ebnbgo.

Ruiz, S., Ruiz San Miguel, F. J. \& Galindo, F. (2016). Los millennials universitarios y su interacción con el social mobile. Fonseca, Journal of Communication, 12, 97-116. Recuperado de http:// dx.doi.org/10.14201/fjc20161297116.

Saló, G. (2003). ¿Qué es eso del formato? Cómo nace y se desarrolla un programa de televisión. Barcelona: Gedisa Editorial.

Samsung \& Ipsos (2016/11/22). Momentos alrededor de la TV. Noticias Samsung. Recuperado de https://goo.gl/h2WykM

Scolari, C. (2008). Hacia la hipertelevisión. Los primeros síntomas de una nueva configuración del dispositivo televisivo. Diálogos de la Comunicación, 77, 01-09. Recuperado de https:// goo.gl/8nnYrN

Scolari, C. (2013/06/15). La TV después del broadcasting: hipertelevisión, redes y nuevas audiencias. Post en blog Intermediaciones. Recuperado de https://goo.gl/oKb5Nv.

Scolari, C. (2017/10/28). Transmedia is dead. Long live transmedia! Post en blog Intermediaciones. Recuperado de https://goo.gl/puwFuT. 
Tejerina, B., Aldekoa, E., \& Garcia, J. (2017). La construcción de la subjetividad juvenil. Experiencias y estilos de vida ente los jóvenes. En Benedicto, J. (Dir.), Informe Juventud en España 2016 (pp 329-418). Madrid: Instituto de la Juventud. Recuperado de https://goo.gl/Bqgppf. The Future Group, Fremantle Media, Ross Video y Epic Games desarrollan el concepto de realidad mixta interactiva en 'Lost in Time' (2017/05/03). Panoramaaudiovisual.com. Recuperado de https://bit.ly/2uHFYjm 